\title{
Antitumor and immunomodulatory activities of thiosemicarbazones and 1,3-Thiazoles in Jurkat and HT-29 cells
}

\author{
Thiago André R. dos Santos ${ }^{\mathrm{a}}$, Aline Caroline da Silva ${ }^{\mathrm{a}}$, Elany Barbosa Silva ${ }^{\mathrm{b}}$, \\ Paulo André Teixeira de Moraes Gomes ${ }^{\mathrm{b}}$, José Wanderlan Pontes Espíndola ${ }^{\mathrm{b}}$, \\ Marcos Veríssimo de Oliveira Cardoso ${ }^{\mathrm{b}}$, Diogo Rodrigo Magalhaes Moreira ${ }^{\mathrm{c}}$, \\ Ana Cristina Lima Leite ${ }^{\mathrm{b}, *}$, Valéria R.A. Pereira ${ }^{\mathrm{a}, *}$
}

\footnotetext{
${ }^{a}$ Fundação Oswaldo Cruz, Centro de Pesquisa Aggeu Magalhães, Laboratório de Imunogenética, CEP 50670-420, Recife, PE, Brazil

b Universidade Federal de Pernambuco, Departamento de Ciências Farmacêuticas, CEP 50740-520, Recife, PE, Brazil

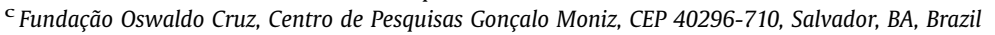

\section{A R T I C L E I N F O}

\section{Article history:}

Received 7 December 2015

Received in revised form 20 May 2016

Accepted 23 May 2016

\section{Keywords:}

Drug development

Cancer

Immune system

1,3-thiazoles

Thiosemicarbazones

Cell death

\begin{abstract}
A B S T R A C T
Cancer remains a high incidence and mortality disease, causing around 8.2 million of deaths in the last year. Current chemotherapy needs to be expanded, making research for new drugs a necessary task. Immune system modulation is an emerging concept in cancer cell proliferation control. In fact, there are a number of mechanisms underlying the role immune system plays in tumor cells. In this work, we describe the structural design, synthesis, antitumor and immunomodulatory potential of 31 new 1,3thiazole and thiosemicarbazone compounds. Cisplatin was used as anticancer drug control. Cytotoxicity against J774A.1 macrophages and antitumor activity against HT-29 and Jurkat cells was determined. These 1,3-thiazole and thiosemicarbazone compounds not only exhibited cytotoxicity in cancer cells, but were able to cause irreversible cancer cell damage by inducing necrosis and apoptosis. In addition, these compounds, especially pyridyl-thiazoles compounds, regulated immune factors such as interleukin 10 and tumor necrosis factor, possible by directing immune system in favor of modulating cancer cell proliferation. By examining their pharmacological activity, we were able to identify new potent and selective anticancer compounds.
\end{abstract}

(c) 2016 Elsevier Masson SAS. All rights reserved.

\section{Introduction}

Immune system modulation is an emerging concept in cancer cell proliferation control. In fact, there are a number of mechanisms underlying the role immune system plays in tumor cells. The most well-known processes involve minimizing metastasis by attenuating pro-angiogenic cytokines expression, or alternatively by upregulating expression of endothelial factors that are crucial for angiogenic process in metastasis. In addition, enhancing antitumor immunity mediated by interferon- $\gamma$ and interleukins can reduce cancer cell development. In view of this, discovery of anticancer and immunomodulating agents is a line of research that is receiving much attention [1-4].

\footnotetext{
* Corresponding authors.

E-mail addresses: thiago.andre.ufpe@gmail.com (T.A.R. dos Santos), acllb2003@yahoo.com.br (A.C. da Silva), valeria@cpqam.fiocruz.br (V.R.A. Pereira).
}

Among anticancer and immunomodulatory drug candidates that have entered into clinical trials, the majority are synthetic compounds, especially heterocyclic derivatives. Examples are Thalidomide, Imatinib and Sunitinib. Following this direction, phthalimide has commonly been employed in design of potential anti-inflammatory, immunomodulatory, antiangiogenic, and antitumor drugs. Given this promising outlook, the strategy of molecular hybridization, using phthalimide as a pharmacophoric fragment has figured prominently in recent research and given rise to many successful outcomes. Our research group has discovered potent and selective anticancer and anti-inflammatory compounds by hybridizing two distinct structural domains: phthalimide and another heterocyclic ring. This has led to the identification of various SARs and the discovery of a new potent hybrid compound containing thiosemicarbazone and 1,3-thiazole moieties, which were observed as having selective toxicity against tumor cells $[1,5,6]$.

Bearing in mind the molecular biophores outlined above and the remarkable pharmacological properties observed in 1,3- 
thiazole and thiosemicarbazone compounds, we here describe the design, synthesis and pharmacological evaluation of 31 new potential antitumor and immunomodulatory agents. These 1,3thiazole and thiosemicarbazones not only exhibited cytotoxicity in cancer cells, but were able to cause irreversible cancer cell damage by inducing necrosis and apoptosis. In addition, especially pyridylthiazoles compounds, regulated immune factor such as interleukin 10 and tumor necrosis factor, possible by halting the immune system in favor of modulating cancer cell proliferation.

\section{Material and methods}

\subsection{Compounds}

Compounds were obtained from LPQM (Laboratory of planning in Medicinal Chemistry). In general, compounds were developed in two reaction steps: a condensation between ketones and different thiosemicarbazides; and a cyclization of the thiosemicarbazones obtained in the preceding step with different $\alpha$-halogen-acetophenones [7]. The pyridyl-thiosemicarbazones 3a-c, aryl-thiosemicarbazone (6) and phthalyl-thiosemicarbazones $(\mathbf{9 a}, \mathbf{9 b})$ were prepared from the reaction between thiosemicarbazides (1a-c) and pyridyl-ketone (2), the aryl-ketone (5) and phthalyl ketone (8), respectively (Fig. 1). The thiosemicarbazones obtained were treated with different $\alpha$-halogen-acetophenones to obtain derivatives of 1,3-thiazoles $(\mathbf{4 a}-,(\mathbf{7} \mathbf{a}-\mathbf{j})$ and $(\mathbf{1 0} \mathbf{a}-\mathbf{j})$. All compounds were chemically characterized and presented purity of $>95 \%$ [8].

\subsection{Cell culture}

Colorectal cancer cell line HT-29 and J774A.1 macrophage cell line was cultured in DMEM medium (Cultilab) containing 10\% heat-inactivated fetal bovine serum, $100 \mathrm{U} / \mathrm{mL}$ penicillin $\mathrm{G}$, and $2 \mathrm{mMl}$-glutamine in a humidified atmosphere of $5 \% \mathrm{CO}_{2}$ in air at $37^{\circ} \mathrm{C}$. Jurkat cells (human acute $\mathrm{T}$ lymphocytic leukemia) cultured in RPMI 1640 medium (Sigma) containing 10\% heat-inactivated fetal bovine serum, $100 \mathrm{U} / \mathrm{mL}$ penicillin $\mathrm{G}$, and $2 \mathrm{mMl}$-glutamine in a humidified atmosphere of $5 \% \mathrm{CO}_{2}$ in air at $37^{\circ} \mathrm{C}$. Both cell lines used in this work were obtained from cell bank of Rio de Janeiro (BCRJ). Culture medium was changed 2-3 days and subcultured when cell population density reached to $70-80 \%$ confluence.

\subsection{Cytotoxicity assessment by MTT assay}

MTT-tetrazolium reduction assay was used to evaluate effects of compounds against HT-29, Jurkat and J774A.1 cells [9]. Briefly, $1 \times 10^{5}$ cells/well were added in 96-well plates with appropriated medium and incubated for $24 \mathrm{~h}\left(37^{\circ} \mathrm{C}\right.$ and $\left.5 \% \mathrm{CO}_{2}\right)$. Compounds<smiles>[Y]c1nc(N/N=C(\CC)c2cccc(Br)c2)sc1[R]</smiles><smiles>CCCCCCC(=O)c1cccc(Br)c1</smiles><smiles>[R]NC(=S)NN</smiles><smiles>O=CCN1C(=O)c2ccccc2C1=O</smiles><smiles>CC(=O)c1ccc[n-]1</smiles><smiles>[R]NC(=S)N/N=C/CN1C(=O)c2ccccc2C1=O</smiles>

Phthalyl - thiosemicarbazone<smiles>[R]NC(=S)N/N=C(\Br)c1ccccn1</smiles><smiles>CCC</smiles><smiles></smiles>

Pyridyl - 1,3-thiazoles<smiles></smiles>

Phthalyl - 1,3-thiazoles

\begin{tabular}{|c|c|c|c|c|c|c|c|c|c|}
\hline Compounds & $\mathbf{R}_{1}$ & $\mathbf{R}$ & Ar & Compounds & $\mathbf{R}^{\prime}$ & Ar & Compounds & $\mathrm{R}$ & Ar \\
\hline 1a & - & H & - & $7 a$ & - & $\mathbf{P h}$ & $9 a$ & H & \\
\hline $1 \mathrm{~b}$ & - & $\mathrm{CH}_{3}$ & - & $7 \mathbf{b}$ & - & 4-Me-Ph & 9b & Ph & - \\
\hline $1 \mathrm{c}$ & - & $\mathbf{P h}$ & - & $7 \mathrm{c}$ & - & 4-MeO-Ph & $10 \mathrm{~b}$ & - & $\mathbf{P h}$ \\
\hline 3a & $\mathrm{CH}_{3}$ & $\mathrm{CH}_{3}$ & - & $7 \mathrm{~d}$ & $\mathrm{CH}_{3}$ & 4-Br-Ph & $10 \mathrm{c}$ & - & 4-Me-Ph \\
\hline 3b & $\mathrm{CH}_{3}$ & H & - & $7 \mathrm{e}$ & & $3-\mathrm{NO}_{2}-\mathrm{Ph}$ & 10d & - & 4-MeO-Ph \\
\hline $3 \mathrm{c}$ & $\mathrm{Ph}$ & $\mathrm{CH}_{3}$ & 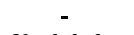 & $7 \mathrm{f}$ & - & $4-\mathrm{NO}_{2}-\mathrm{Ph}$ & $10 \mathrm{e}$ & - & 3-NO2-Ph \\
\hline $4 a$ & $\mathrm{CH}_{3}$ & $\mathrm{CH}_{3}$ & Naphthalene & $7 \mathrm{~g}$ & - & 4-F-Ph & $10 \mathrm{f}$ & - & 4-NO2-Ph \\
\hline $4 \mathrm{~b}$ & $\mathrm{CH}_{3}$ & $\mathrm{CH}_{3}$ & $4-\mathrm{NO}_{2} \mathrm{Ph}$ & $7 \mathrm{~h}$ & - & 4-Cl-Ph & $10 \mathrm{~g}$ & - & 4-Cl-Ph \\
\hline $4 \mathrm{c}$ & $\mathrm{CH}_{3}$ & $\mathrm{CH}_{3}$ & 4-MeO-Ph & $7 \mathrm{i}$ & - & 3,4-diCl-Ph & $10 \mathrm{~h}$ & - & 4-Br-Ph \\
\hline $4 d$ & $\mathrm{CH}_{3}$ & $\mathrm{CH}_{3}$ & 4-Cl-Ph & $7 j$ & - & 2,4-diCl-Ph & $10 \mathrm{i}$ & - & 4-F-Ph \\
\hline $4 e$ & $\mathrm{CH}_{3}$ & $\mathrm{CH}_{3}$ & 4-Br-Ph & & & & $10 \mathrm{j}$ & - & 3,4-diCl-Ph \\
\hline $4 f$ & $\mathrm{CH}_{3}$ & $\mathrm{CH}_{3}$ & 4-F-Ph & & & & & & \\
\hline
\end{tabular}

Fig. 1. General synthetic procedure. 
were then added in different concentrations ( 1 to $100 \mu \mathrm{g} / \mathrm{mL}$ ) and incubated for $72 \mathrm{~h}$. Cisplatin was used as a reference drug. Two hours before the end of the incubation time, $25 \mu \mathrm{L}$ MTT (3-(4,5Dimethylthiazol-2-yl)-2,5-diphenyltetrazoliumbromide, $5 \mathrm{mg} / \mathrm{mL}$ in PBS) was added to each well. Culture medium was removed and $100 \mu \mathrm{L}$ of DMSO were added. The amount of formazan was determined by measuring the absorbance at $570 \mathrm{~nm}$ [9]. Concentration leading to $50 \%$ inhibition of viability $\left(\mathrm{CC}_{50}\right)$ was calculated by regression analysis.

\subsection{Flow cytometry assay}

HT-29 and Jurkat cells $\left(1 \times 10^{6}\right.$ cells $\left./ \mathrm{mL}\right)$ were treated $(72 \mathrm{~h}$, $37^{\circ} \mathrm{C}, 5 \% \mathrm{CO}_{2}$ ) with compounds in its respective $\mathrm{CC}_{50}$, obtained in previous experiments. Briefly, tumor cells were harvested, washed with PBS, re-suspended in Annexin $\mathrm{V}$ biding buffer (eBioscience, San Diego, CA, USA) and stained with propidium iodide (PI) and annexin V-FITC (eBioscience, San Diego, CA, USA) according to manufacturer instructions. The cells were immediately analyzed by flow cytometry (FACSCalibur ${ }^{\mathrm{TM}}$, BD BioSciences, San Jose, CA, USA) [10]. Results were analyzed by BD FlowJo 7.6 software.

\subsection{Immunomodulatory activity}

J774A.1 macrophages were stimulated with compounds for 24 , 48 and $72 \mathrm{~h}$ in its respective $\mathrm{CC}_{50}$ values and culture supernatants were used to measurement of cytokine production [9]. Lipopolysaccharide (LPS at $50 \mathrm{ng} \mathrm{mL-1)}$ was used as positive control, while cells without either LPS or compounds were used as negative control. Concentration of TNF and IL-10 was measured using sandwich enzyme-linked immunosorbent assay (ELISA), according to the manufacturer's suggested protocols (BD OptEIA ${ }^{\mathrm{TM}}$, San Jose, CA, USA). Absorbance was read at $415 \mathrm{~nm}$ using a spectrophotometer (Multiskan ${ }^{\mathrm{TM}}$ FC Microplate Photometer, Thermo Scientific, San Jose, CA, USA).

\subsection{Statistical analysis}

All experiments were done in triplicate. Data were analyzed by one-way analysis of variance (ANOVA) followed by Dunnett's test $(P<0.05)$. GraphPad Prism 5.0 (GraphPad, California, EUA) was used for all analysis.

\section{Results}

\subsection{Antitumor activity on Jurkat and HT-29 cell lines}

Using MTT assay we observed that compounds demonstrated antitumor activity in both Jurkat and HT-29 cells. Compounds tested showed a dose-dependent effect (data not shown). All pyridyl-thiosemicarbazones and pyridyl-thiazoles series showed low $\mathrm{CC}_{50}$ value in HT-29 and Jurkat cells when compared with cisplatin - 179 and $89,5 \mu \mathrm{M}$, respectively (Table 1 ). The lower $\mathrm{CC}_{50}$ value in HT-29 and Jurkat cells was observed with compound $\mathbf{3 b}$ $(17.18 \mu \mathrm{M})$ and compound $7 \mathbf{e}(2.79 \mu \mathrm{M})$ respectively.

\subsection{Cell death induction}

Once observed that compounds had an antitumor effect, and after determination of $\mathrm{CC}_{50}$ value for each compound, we incubated HT-29 and Jurkat cells with these compounds in its respective $\mathrm{CC}_{50}$ values for $72 \mathrm{~h}$ aiming to evaluate the kind of cell death induced. Cells were stained with annexin V-FITC (AN) and propidium iodide (PI) and analyzed by flow cytometry.

Untreated HT-29 cells presented a lower staining with either AN or PI, demonstrating cell viability. Saponin, used as cell death
Table 1

Compounds utilized in this study and their cytotoxicity in J774A.1 Macrophages, HT29 and Jurkat cell lines.

\begin{tabular}{|c|c|c|c|}
\hline Compound & J774A.1 $\mathrm{CC}_{50}(\mu \mathrm{M})$ & HT-29 $\mathrm{CC}_{50}(\mu \mathrm{M})$ & Jurkat $\mathrm{CC}_{50}(\mu \mathrm{M})$ \\
\hline $3 a$ & 21,77 & 83,09 & 14,91 \\
\hline 3b & 182,57 & 17,18 & 32,80 \\
\hline $3 c$ & 21,36 & 29,46 & ND \\
\hline $4 a$ & 30,35 & 57,83 & 16,23 \\
\hline $4 b$ & 36,05 & 65,62 & 21,30 \\
\hline 4c & 19,99 & 108,25 & 19,59 \\
\hline 4d & 20,32 & 78,87 & 28,18 \\
\hline $4 e$ & 33,60 & 51,29 & 21,54 \\
\hline $4 f$ & 11,65 & 25,22 & ND \\
\hline 6 & 51,05 & 153,67 & 67,82 \\
\hline $7 a$ & 75,90 & 57,49 & 74,37 \\
\hline 7b & 113,60 & 24,13 & 116,63 \\
\hline 7c & 114,96 & 61,97 & 113,83 \\
\hline 7d & 21,95 & 58,34 & 110,66 \\
\hline $7 e$ & 40,13 & 21,02 & 2.79 \\
\hline $7 f$ & 67,47 & ND & 125,69 \\
\hline $7 g$ & 6,50 & 79,62 & 117,88 \\
\hline 7h & ND & 126,75 & 406,65 \\
\hline $7 \mathbf{i}$ & 124,76 & 127,59 & 271,53 \\
\hline $7 \mathbf{j}$ & 75,37 & 18,29 & 25,13 \\
\hline 9b & 28,66 & 13,44 & 88,81 \\
\hline $10 a$ & 69,33 & 172,53 & 17,48 \\
\hline $10 b$ & 37,01 & 21,05 & 83,60 \\
\hline $10 c$ & 41,03 & 17,84 & 23,42 \\
\hline $10 d$ & 40,51 & 22,09 & 114,49 \\
\hline $10 \mathrm{e}$ & 47,38 & 21,28 & 21,22 \\
\hline $10 f$ & 26,47 & 273,22 & 21,53 \\
\hline $10 \mathrm{~g}$ & 30,07 & 114,45 & 11,54 \\
\hline $10 \mathrm{~h}$ & 21,20 & 95,77 & ND \\
\hline $10 \mathrm{i}$ & 26,57 & 129,71 & 8,54 \\
\hline $10 \mathrm{j}$ & ND & 0,00 & 23,99 \\
\hline Cisplatin & 58,98 & 179,07 & 89,47 \\
\hline
\end{tabular}

Note: ND: Not Determined.

positive control, caused a high staining ( $>90 \%)$ with PI, indicating cell death by necrosis, as expected. Pyridyl-thiazoles compounds caused higher labeling with AN, under the experimental conditions applied, indicating cell death predominantly by apoptosis. An increase of double staining (AN-PI) was detected after incubation with Phthalyl-thiazoles and Pyridyl-thiazoles, indicating the occurrence of cell death by necrosis or late apoptosis (Fig. 2).

Jurkat untreated cells showed low staining with either AN or PI. The cell treatment with the commercial drug cisplatin caused a double staining (AN-PI) increase. Jurkat cells presented a high double staining with high percentage of PI labeling, for pyridylthiazoles. Compound 10c led to an increasing of AN staining, twice higher than untreated control. 10a and $\mathbf{3 b}$ compounds induced a high increasing of double staining in Jurkat cells. Results are shown in Fig. 3.

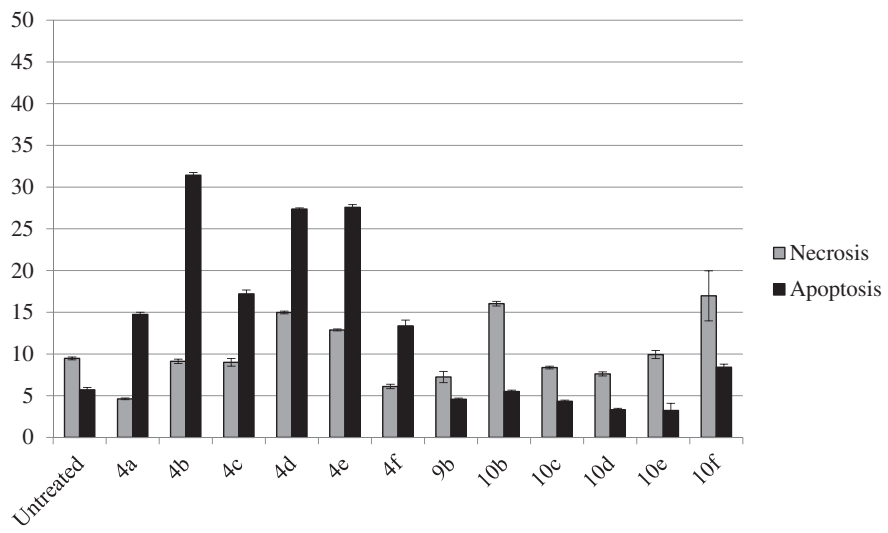

Fig. 2. Percentage of HT-29 cells labeled for necrosis and apoptosis, after $72 \mathrm{~h}$ of incubation with the compounds. 


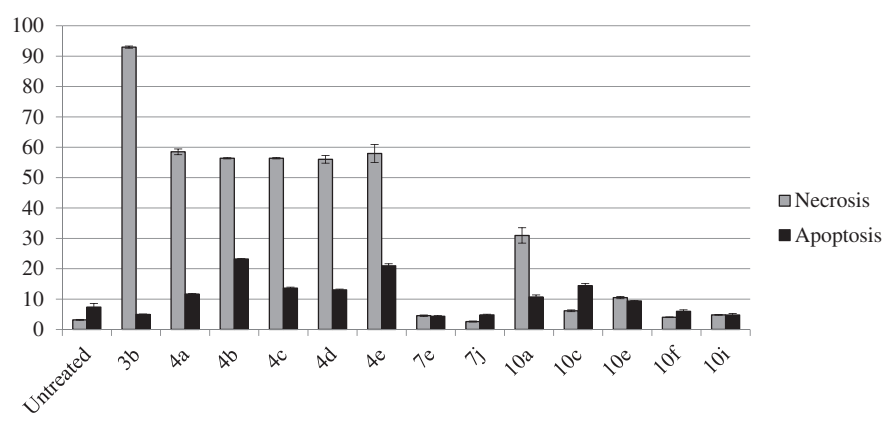

Fig. 3. Percentage of Jurkat cells stained for necrosis and apoptosis, after $72 \mathrm{~h}$ of incubation with the compounds.

\subsection{Cytotoxicity effect and immunomodulatory activity on macrophages}

Cytotoxicity in J774A.1 cells was done by MTT assay and $\mathrm{CC}_{50}$ results were used for stimulation of cultures. $\mathrm{CC}_{50}$ results varied between 6,5 and $182,57 \mu \mathrm{M}$, for $\mathbf{7 g}$ and $\mathbf{3 b}$, respectively. Cisplatin showed a $\mathrm{CC}_{50}$ of $58.98 \mu \mathrm{M}$. All $\mathrm{CC}_{50}$ results are shown in Table 1.

Immunomodulatory activity was evaluated by production of cytokines IL-10 and TNF. This quantification was assessed by ELISA assay. For this purpose, J774A.1 macrophages supernatants of culture were collected after incubation with compounds for 24,48 and $72 \mathrm{~h}$. Results are showed below.

TNF production was observed for all compounds tested after $48 \mathrm{~h}$ of incubation, however, significant values were observed only for $\mathbf{6}, \mathbf{7 a}, \mathbf{7 f}, \mathbf{7 h}, \mathbf{7 i}, \mathbf{7 j}$, all pyridyl-thiosemicarbazones, pyridylthiazoles and phthalyl-thiazoles (except 10f). Similar results were observed after $72 \mathrm{~h}$ of incubation. Results are shown in Figs. 4 and 5.

After $24 \mathrm{~h}$ of incubation with compounds $\mathbf{4 c}$ and $4 \mathrm{~d}$ was observed a significant $(\mathrm{p}<0.0001)$ decrease in IL-10 production, when compared to untreated group. Inhibition of production of this cytokine was sustained with $\mathbf{4 c}$ after $48 \mathrm{~h}$ of incubation. On the other hand, 7d, 7f, 7g, 10g, 10h, 10j increased this cytokine production after $48 \mathrm{~h}$ (Figs. 6 and 7). It was not detected production of IL-10 after $72 \mathrm{~h}$ of treatment.

\section{Discussion}

Despite great efforts made by public and private organizations cancer's characteristics, as severity and often lethality, has persisted over the years [11]. Development of new cancer treatments remains a challenging process, diverse therapy strategies have been developed and tried, and medicinal chemistry is one of this approaches [12]. In this context, several compounds has been noted for its activity in various diseases, including cancer [13].
These compounds include thiosemicarbazones, thiazoles and phthalimides, molecules tested in this study. The choice of these compounds for development of pre-clinical trials are based on the broad spectrum of biological activities related to them, as well as the effects on components of immune system such as cytokines [14,15].

In this work, four classes of compounds were screened for its antitumor activities, and its actions on immune cells. Cisplatin, used as a control, is one of the most remarkable success in the treatment of cancer [16]. It is expected that a potential anticancer drug to stimulate protective immunity against the tumor and in favor of the host [17].

A screening was performed with J774A.1 macrophages, through MTT assay. In this assay, only metabolically viable cells can reduce MTT by mitochondrial dehydrogenases leading to formation of formazan crystals. These experiments aimed to assess cytotoxicity of compounds in this important cell of immune system, present in microenvironment of practically all solid tumors [18]. It is known that macrophages may play both pro and anti-tumor role, due to its polarization capability and high plasticity [19-21]. Faced with this problem, it constitutes an important approach to evaluate whether tested compounds contribute to cytotoxicity of macrophages.

Cytotoxic effect of compounds when treating tumor cells was superior to the observed after treatment with cisplatin. These results showed that these compounds have a potential as a therapeutic tool, despite the cytotoxicity observed in macrophages. The present data showed that there is a structurerelationship for synthetic compounds tested. The biological activities of compounds are apparently related to the types of modifications on scaffold molecules. Therefore, other experiments were performed, aiming to elucidate this potential in this tumor cell lines.

Antitumor treatment can cause different cell death to neoplastic cells, depending on the lethal stimuli generated [22] Apoptosis is a strongly regulated process that can be initiated by both intracellular stress signals and extracellular ligands [23]. Apoptosis is morphologically characterized by cell shrink, pyknosis and eventually fragmentation of apoptotic bodies [24]. Inactivation of apoptosis is a central event in cancer development, and its activation, by treatment approaches, can present benefits in patient prognostic [25]. In contrast, necrosis has been considered as an uncontrolled cell death pathway, characterized by cytoplasmic vacuolization, loss of plasma membrane integrity and cell swelling [23].

After observation that compounds had a considerable cytotoxic effect on tumor cell lines, induction of necrosis and apoptosis was assessed for HT-29 and Jurkat cell lines.

All compounds tested increase significantly the labeling for apoptosis and necrosis. In fact, the triggering of these two types of cell death can have beneficial effects on clinical [23], and these results support the need for further studies in vitro and in vivo in

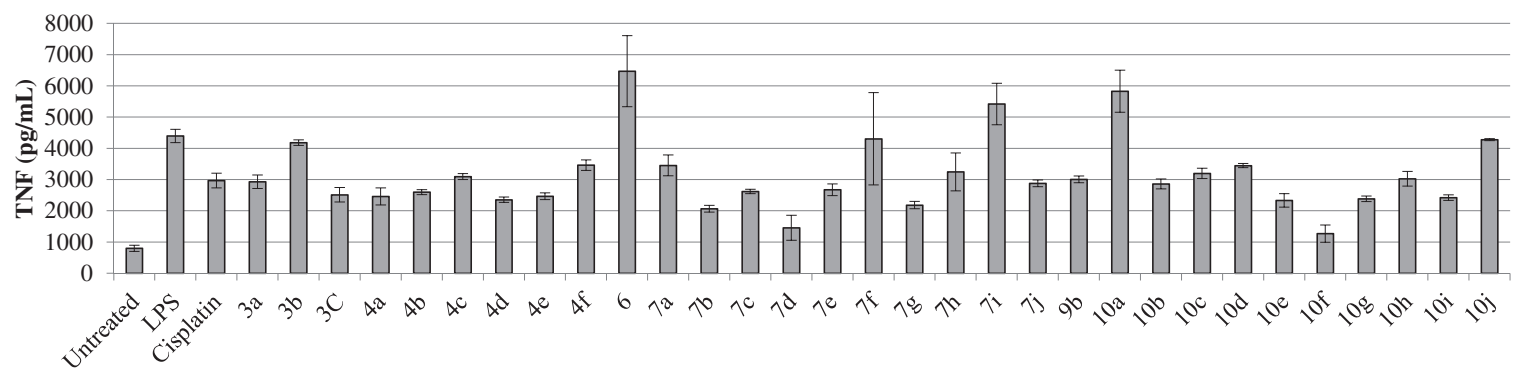

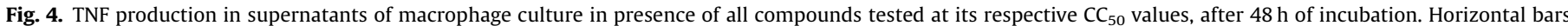
represent standard derivation.

Note: Increase was significant for 3a, 3b, 3c, 4a, 4b, 4c, 4d, 4e, 4f, 6, 7a, 7f, 7h, 7i, 7j, 10a, LPS and Cisplatin. P $<0.0001$ 


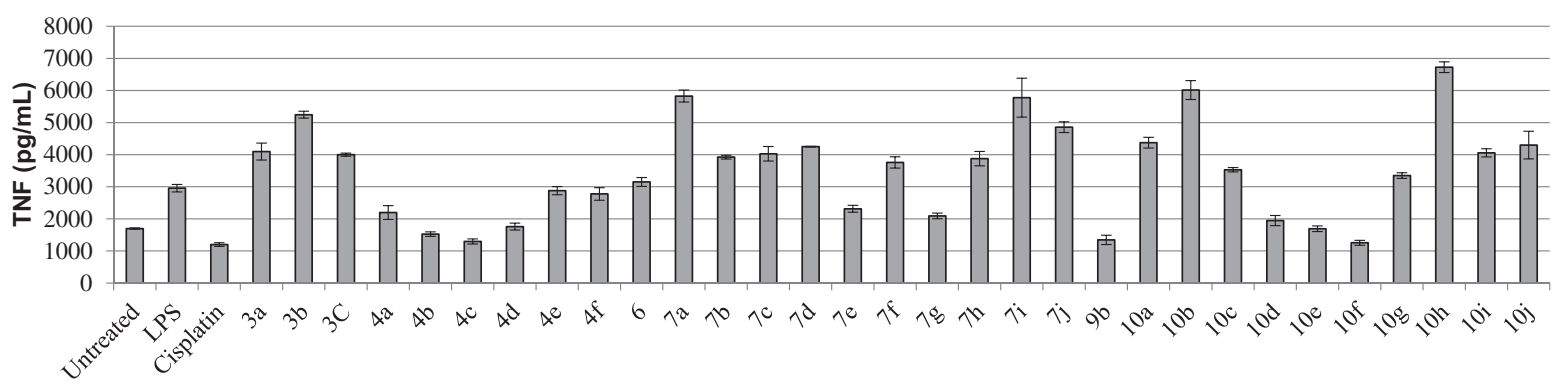

Fig. 5. TNF production in supernatants of macrophage culture after $72 \mathrm{~h}$ of incubation. Horizontal bars represent standard derivation. Note: Increase was significant for 3a, 3b, 3c, 4a, 4e, 4f, 6,7a, 7b, 7c, 7d, 7e, 7f, 7g, 7h, 7i, 7j, 10a, 10b, $10 \mathbf{c}, 10$ g, $10 \mathrm{~h}, 10 \mathrm{i}, 10 \mathbf{j}$ and LPS. P $<0.0001$.

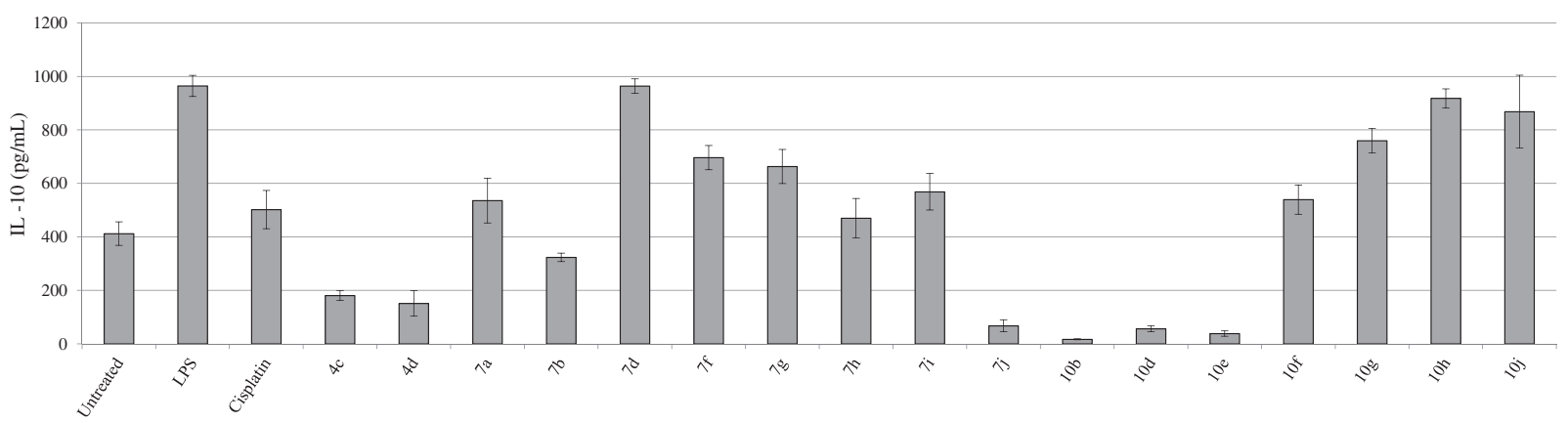

Fig. 6. IL-10 production in supernatants of macrophage culture after $24 \mathrm{~h}$ of incubation. Horizontal bars represent standard derivation.

Note: Increase was significant for $\mathbf{7 d}, \mathbf{7 f}, \mathbf{7 g}, \mathbf{1 0 g}, \mathbf{1 0 h}, \mathbf{1 0 j}$, LPS and Cisplatin. $\mathrm{P}<0.0001$. Decrease was significant for $\mathbf{4 c}, \mathbf{4 d}, \mathbf{7 j}, \mathbf{1 0 b}, \mathbf{1 0 d}$ and $\mathbf{1 0 e}$. P $<0.0001$.

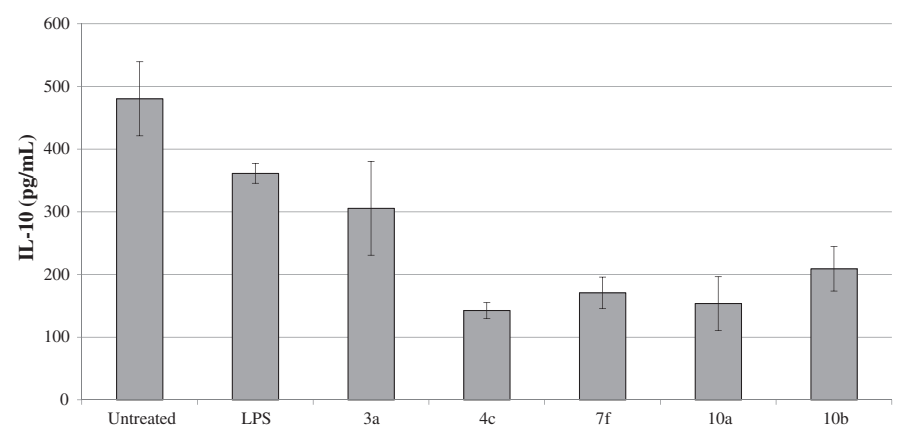

Fig. 7. IL-10 production in supernatants of macrophage culture after $48 \mathrm{~h}$ of incubation. Horizontal bars represent standard derivation. Note: Decrease was significant for 3a, 4c, 7f, 10a, 10b. $\mathrm{P}<0.0001$.

order to identify the mechanism of action of this series compounds.

The presence of cytokines are an important component in tumor microenvironment and often more important than the cellular content. The type and amount of cytokines produced in this microenvironment may be critical in tumor development and progression [3].

Cytokine production after incubation with compounds was evaluated with J774A.1 macrophages. IL-10 and TNF production were assessed after 24,48 and $72 \mathrm{~h}$ of incubation.

Among untreated group, production of IL-10 was observed after 24 and $48 \mathrm{~h}$. Its known that under stationary state tissue macrophages presents intrinsic anti-inflammatory functions [26].

IL-10 exerts it function through inhibitory activity on macrophages and dendritic cells. IL-10 inhibits IL-12 production by activated macrophages in addition to down regulate MHC-II expression by this cells [27]. IL-10 reduction might be considered a desirable phenomenon, mainly if it happens in tumor microenvironment, since that several pro tumor effects have been associated with this cytokine $[28,29]$.

Historically, TNF was the first cytokine used in cancer treatment [30]. Apart of cancer context, TNF was identified as a main regulator of inflammation and a key in cytokine network [31]. In cancer context, this cytokine can present a dichotomous action and can actuate as a pro or antitumor agent, in diverse contexts. For instance, this pro-inflammatory cytokine is an important factor involved in initiation, proliferation, angiogenesis and metastasis of diverse cancer types [32]. Several malign cells constitutively produce small quantities of TNF [31]. Those observations, and TNF roles in cancer development and progression might shade anticancer potential of this cytokine [30]. Defining TNF role in cancer therapy remains a challenging process due to its pleiotropic nature that might stimulate multiple complex and interconnected pathways, often involved in opposite phenomena [30].

Results obtained reveal that some compounds have good activity as immunomodulators on J774A.1 macrophage. Understanding mechanisms by which a favorable immune context can be 
developed and maintained is essential for guiding innovative therapies [33]. New approaches on cancer treatment should consider, and take advantage of mechanisms that interfere in macrophages in several levels, as in attraction, differentiation and activation of this cells [19].

Thus, several series of compounds tested in this work deserve to be further investigated, since it was observed for several of them, low cytotoxic effect on macrophages, cytotoxic action against tumor cells, as well as necrosis/apoptosis induction and stimulation of important cytokines production. Results show that these compounds could represent promising prototype for development of new pharmacological agents. As perspectives, further elucidation of its mode of action and its effects in vivo models is needed.

\section{Conclusions}

Anticancer drug development is substantially necessary. By examining pharmacological activity of a set of thiosemicarbazone and 1,3-thiazole, we were able to identify new potent and selective anticancer compounds, such as $4 \mathrm{a}, 7 \mathrm{c}, 10 \mathrm{e}$ and $3 \mathrm{~b}$ as most potent anticancer and immunomodulatory agent of each series. These compounds show low cytotoxicity against macrophages and modulated cytokines production. Therefore, these 1,3-thiazole and thiosemicarbazone compounds not only exhibited cytotoxicity in cancer cells, but were able to cause irreversible cancer cell damage by inducing necrosis and apoptosis. It would be worthwhile to conduct further optimization studies with a view to improving the antitumor properties of this 1,3-thiazole and thiosemicarbazone prototypes.

\section{Acknowledgements}

We would like to thank the Brazilian National Research Council (CNPq), Research Foundation of Pernambuco State (FACEPE) and FIOCRUZ for the financial support.

\section{Appendix A. Supplementary data}

Supplementary data associated with this article can be found, in the online version, at http://dx.doi.org/10.1016/j. biopha.2016.05.038.

\section{References}

[1] A.C.L. Leite, F.F. Barbosa, M.V. de, O. Cardoso, D.R.M. Moreira, L.C.D. Coêlho, E.B. da Silva, et al., Phthaloyl amino acids as anti-inflammatory and immunomodulatory prototypes, Med. Chem. Res. 23 (2014) 1701-1708, doi: http://dx.doi.org/10.1007/s00044-013-0730-1.

[2] M.A. Swartz, N. Iida, E.W. Roberts, S. Sangaletti, M.H. Wong, F.E. Yull, et al, Tumor microenvironment complexity: emerging roles in cancer therapy, Cancer Res. 72 (2012) 2473-2480, doi:http://dx.doi.org/10.1158/0008-5472 CAN-12-0122.

[3] S.I. Grivennikov, F.R. Greten, M. Karin, Immunity, inflammation, and cancer, Cell 140 (2010) 883-899, doi:http://dx.doi.org/10.1016/j.cell.2010.01.025.

[4] W.J. Lesterhuis, J.B.A.G. Haanen, C.J.A. Punt, Cancer immunotherapy - revisited, Nat. Rev. Drug Discov. 10 (2011) 591-600, doi:http://dx.doi.org/10.1038/ $\operatorname{nrd} 3500$.

[5] L.C.D. Coêlho, M.V. de, O. Cardoso, D.R.M. Moreira, P.A.T. de, M. Gomes, S.M.T Cavalcanti, A.R. Oliveira, et al., Novel phthalimide derivatives with TNF- $\alpha$ and IL-1 $\beta$ expression inhibitory and apoptotic inducing properties, Medchemcomm 5 (2014) 758, doi:http://dx.doi.org/10.1039/c4md00070f.

[6] C. Pessoa, P.M.P. Ferreira, L.V.C. Lotufo, M.O. de Moraes, S.M.T. Cavalcanti, L.C.D. Coêlho, et al., Discovery of phthalimides as immunomodulatory and antitumor drug prototypes, ChemMedChem 5 (2010) 523-528, doi:http://dx.doi.org/ $10.1002 / \mathrm{cmdc} .200900525$.

[7] M.V de O. Cardoso, L.R.P. de Siqueira, E.B. da Silva, L.B. Costa, M.Z. Hernandes, M.M. Rabello, et al., 2-Pyridyl thiazoles as novel anti-Trypanosoma cruzi agents: structural design, synthesis and pharmacological evaluation, Eur. J. Med. Chem. 86 (2014) 48-59, doi:http://dx.doi.org/10.1016/j. ejmech.2014.08.012.
[8] P.A.T. de M. Gomes, A.R. Oliveira, M.V. de O. Cardoso, E. de F. Santiago, M. deOBarbosa, L.R.P. deSiqueira, et al., Phthalimido-thiazoles as building blocks and their effects on the growth and morphology of Trypanosoma cruzi, Eur. J. Med. Chem. 111 (2016) 46-57, doi:http://dx.doi.org/10.1016/j. ejmech.2016.01.010.

[9] M.E.S.B. Barros, J.C.R. Freitas, J.M. Oliveira, C.H.B. Da Cruz, P.B.N. Da Silva, L.C.C. De Araújo, et al., Synthesis and evaluation of (-)-Massoialactone and analogues as potential anticancer and anti-inflammatory agents, Eur. J. Med. Chem. 76 (2014) 291-300, doi:http://dx.doi.org/10.1016/j.ejmech.2014.02.013.

[10] E. Augustin, A. Moś-Rompa, D. Nowak-Ziatyk, J. Konopa, Antitumor 1nitroacridine derivative $\mathrm{C}$-1748, induces apoptosis, necrosis or senescence in human colon carcinoma HCT8 and HT29 cells, Biochem. Pharmacol. 79 (2010) 1231-1241, doi:http://dx.doi.org/10.1016/j.bcp.2009.12.012.

[11] A. Kamb, S. Wee, C. Lengauer, Why is cancer drug discovery so difficult? Rev. Nat. Rev. Drug Discov. 6 (2007) 115-120, doi:http://dx.doi.org/10.1038/ $\operatorname{nrd} 2155$.

[12] C.J. Lord, A. Ashworth, Biology-driven cancer drug development: back to the future, BMC Biol. 8 (2010) 38, doi:http://dx.doi.org/10.1186/1741-7007-8-38.

[13] S.J. Sturla, J.J. Irwin, R.N. Loeppky, M.J. Mulvihill, M. Searcey, Chemistry in cancer research: a vital partnership, Cancer Res. 67 (2007) 6539-6543, doi: http://dx.doi.org/10.1158/0008-5472 CAN-07-1619.

[14] S.J. Kashyap, V.K. Garg, P.K. Sharma, N. Kumar, R. Dudhe, J.K. Gupta, Thiazoles: having diverse biological activities, Med. Chem. Res. 21 (2011) 2123-2132, doi: http://dx.doi.org/10.1007/s00044-011-9685-2.

[15] S. Zheng, Q. Zhong, Q. Jiang, M. Mottamal, Q. Zhang, N. Zhu, et al., Discovery of a series of thiazole derivatives as novel inhibitors of metastatic cancer cell migration and invasion, ACS Med. Chem. Lett. 4 (2013) 191-196, doi:http://dx doi.org/10.1021/ml300322n.

[16] N. Pabla, Z. Dong, Cisplatin nephrotoxicity: mechanisms and renoprotective strategies, Kidney Int. 73 (2008) 994-1007, doi:http://dx.doi.org/10.1038/sj. ki.5002786.

[17] M. Dougan, G. Dranoff, Immune therapy for cancer, Annu. Rev. Immunol. 27 (2009) 83-117, doi:http://dx.doi.org/10.1146/annurev. immunol.021908.132544.

[18] G. Solinas, G. Germano, a Mantovani, P. Allavena, Tumor-associated macrophages (TAM) as major players of the cancer-related inflammation, J. Leukoc. Biol. 86 (2009) 1065-1073, doi:http://dx.doi.org/10.1189/jlb.0609385.

[19] M. Heusinkveld, S.H. van der Burg, Identification and manipulation of tumor associated macrophages in human cancers, J. Transl. Med. 9 (2011) 216, doi: http://dx.doi.org/10.1186/1479-5876-9-216.

[20] A. Mantovani, S. Sozzani, M. Locati, P. Allavena, A. Sica, Macrophage polarization: tumor-associated macrophages as a paradigm for polarized M2 mononuclear phagocytes, Trends Immunol. 23 (2002) 549-555, doi:http://dx doi.org/10.1016/S1471-4906(02)02302-5.

[21] F.O. Martinez, L. Helming, S. Gordon, Alternative activation of macrophages: an immunologic functional perspective, Annu. Rev. Immunol. (2009), doi:http:// dx.doi.org/10.1146/annurev.immunol.021908.132532.

[22] O. Kepp, A. Tesniere, F. Schlemmer, M. Michaud, L. Senovilla, L. Zitvogel, et al., Immunogenic cell death modalities and their impact on cancer treatment, Apoptosis 14 (2009) 364-375, doi:http://dx.doi.org/10.1007/s10495-0080303-9.

[23] E.C. de Bruin, J.P. Medema, Apoptosis and non-apoptotic deaths in cancer development and treatment response, Cancer Treat. Rev. 34 (2008) 737-749, doi:http://dx.doi.org/10.1016/j.ctrv.2008.07.001.

[24] R.K. Amaravadi, C.B. Thompson, The roles of therapy-induced autophagy and necrosis in cancer treatment, Clin. Cancer Res. 13 (2007) 7271-7279, doi: http://dx.doi.org/10.1158/1078-0432 CCR-07-1595.

[25] S. Kasibhatla, B. Tseng, Why target apoptosis in cancer treatment? Mol. Cancer Ther. 2 (2003) 573-580. http://www.ncbi.nlm.nih.gov/pubmed/12813137.

[26] P.J. Murray, T.A. Wynn, Protective and pathogenic functions of macrophage subsets, Nat. Rev. Immunol. 11 (2011) 723-737, doi:http://dx.doi.org/10.1038/ nri3073.

[27] S. Lee, K. Margolin, Cytokines in cancer immunotherapy, Cancers (Basel) 3 (2011) 3856-3893, doi:http://dx.doi.org/10.3390/cancers3043856.

[28] E. Itakura, R.-R. Huang, D.-R. Wen, E. Paul, P.H. Wünsch, A.J. Cochran, IL-10 expression by primary tumor cells correlates with melanoma progression from radial to vertical growth phase and development of metastatic competence, Mod. Pathol. 24 (2011) 801-809, doi:http://dx.doi.org/10.1038/ modpathol.2011.5.

[29] L. Zeng, C. O'Connor, J. Zhang, A.M. Kaplan, D.A. Cohen, IL-10 promotes resistance to apoptosis and metastatic potential in lung tumor cell lines, Cytokine. 49 (2010) 294-302, doi:http://dx.doi.org/10.1016/j.cyto.2009.11.015.

[30] L. Bertazza, S. Mocellin, The dual role of tumor necrosis factor (TNF) in cancer biology, Curr. Med. Chem. 17 (2010) 3337-3352. http://www.ncbi.nlm.nih.gov/ pubmed/20712570.

[31] F. Balkwill, Tumour necrosis factor and cancer, Nat. Rev. Cancer 9 (2009) 361371, doi:http://dx.doi.org/10.1038/nrc2628.

[32] W. Lin, M. Karin, A cytokine-mediated link between innate immunity, inflammation, and cancer, J.Clin. Invest. 117 (2007) 1175-1183, doi:http://dx. doi.org/10.1172/JCI31537.data.

[33] W.H. Fridman, F. Pagès, C. Sautès-Fridman, J. Galon, The immune contexture in human tumours: impact on clinical outcome, Nat. Rev. Cancer. 12 (2012) 298306, doi:http://dx.doi.org/10.1038/nrc3245. 